\title{
ARTICLE \\ Chalcomoracin inhibits cell proliferation and increases sensitivity to radiotherapy in human non-small cell lung cancer cells via inducing endoplasmic reticulum stress-mediated
} paraptosis

\author{
Shi-rong Zhang ${ }^{1,2}$, Xiao-chen Zhang ${ }^{3}$, Jia-feng Liang ${ }^{1}$, Hong-ming Fang ${ }^{4}$, Hai-xiu Huang ${ }^{1}$, Yan-yan Zhao $^{1}$, Xue-qin Chen $^{2}$ and \\ Sheng-lin $\mathrm{Ma}^{1,2}$
}

\begin{abstract}
Chalcomoracin (CMR) is a kind of Diels-Alder adduct extracted from the mulberry leaves. Recent studies showed that CMR has a broad spectrum of anticancer activities and induces paraptosis in breast cancer and prostate cancer cells. In this study, we investigated the effects of CMR against human non-small cell lung cancer cells and the underlying mechanisms. We found that CMR dose-dependently inhibited the proliferation of human lung cancer H460, A549 and PC-9 cells. Furthermore, exposure to low and median doses of CMR induced paraptosis but not apoptosis, which was presented as the formation of extensive cytoplasmic vacuolation with increased expression of endoplasmic reticulum stress markers, Bip and Chop, as well as activation of MAPK pathway in the lung cancer cells. Knockdown of Bip with siRNA not only reduced the cell-killing effect of CMR, but also decreased the percentage of cytoplasmic vacuoles in H460 cells. Moreover, CMR also increased the sensitivity of lung cancer cells to radiotherapy through enhanced endoplasmic reticulum stress. In lung cancer $\mathrm{H} 460$ cell xenograft nude mice, combined treatment of CMR and radiation caused greatly enhanced tumor growth inhibition with upregulation of endoplasmic reticulum stress proteins and activation of $\mathrm{pErk}$ in xenograft tumor tissue. These data demonstrate that the anticancer activity and radiosensitization effect of CMR result from inducing paraptosis, suggesting that CMR could be considered as a potential anticancer agent and radiation sensitizer in the future cancer therapeutics.
\end{abstract}

Keywords: chalcomoracin; non-small cell lung cancer; endoplasmic reticulum stress; paraptosis; radiosensitivity

Acta Pharmacologica Sinica (2020) 41:825-834; https://doi.org/10.1038/s41401-019-0351-4

\section{INTRODUCTION}

Lung cancer is the leading cause of cancer death in the world [1]. Despite the rapid development of cancer treatments, including targeting therapy, checkpoint-based immunotherapy and precise radiotherapy, unavoidable drug resistance and rapid distant metastasis are still major obstacles in the clinical management of this disease. Radiation therapy is one of the standard therapeutic strategies in the treatment of most common nonsmall cell lung cancer (NSCLC), especially in patients with unresectable tumors. For patients with local advanced NSCLC, the current multimodal chemotherapy and radiotherapy do not reach satisfactory treatment outcomes for most patients, and the median progression-free survival is only 5-6 months [2-4].

lonizing radiation (IR) can trigger many types of cell death, such as apoptosis, in targeted cancer cells. Apoptosis is induced by surface death receptors, through mitochondrial release of cytochrome $\mathrm{c}$ or by cellular stress induced by drug/radiation exposure. The most common signaling pathways that regulate apoptosis include cell death receptor signaling, the caspase signaling cascade and mitochondrial signaling [5-9]. By acting in parallel or sequentially, autophagy can facilitate and cooperate with apoptosis to drive cell death. Blockage of autophagy by pharmacological inhibitors or knockdown of Beclin 1 and Atg7 expression significantly inhibits apoptosis in cells. When a cell is unable to undergo apoptosis, it may undergo necrotic cell death, which does not involve caspase activation $[10,11]$.

Chalcomoracin (CMR) is a Diels-Alder adduct derived from mulberry leaves. It has been reported that CMR inhibits fatty acid synthesis and can serve as an anti-staphylococcal agent [12-14]. Recent studies have shown that CMR has a broad spectrum of biological activities against human cancers and induces paraptosis in breast cancer and prostate cancer cells. Paraptosis is a type of nonapoptotic cell death characterized by dilation of the endoplasmic reticulum (ER) and/or mitochondria. Although the

\footnotetext{
${ }^{1}$ Department of Translation Medicine Centre, Key Laboratory of Clinical Cancer Pharmacology and Toxicology Research of Zhejiang Province, Affiliated Hangzhou First People's Hospital, Zhejiang University School of Medicine, Hangzhou 310006, China; ${ }^{2}$ Department of Oncology, Affiliated Hangzhou First People's Hospital, Zhejiang University School of

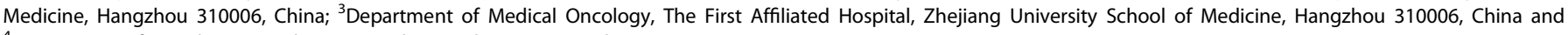
${ }^{4}$ Department of Oncology, Xiaoshan Hospital, Hangzhou 310006, China

Correspondence: Xue-qin Chen (chenlucy1437@aliyun.com) or Sheng-lin Ma (mashenglin@medmail.com.cn)

The authors contributed equally: Shi-rong Zhang, Xiao-chen Zhang
}

Received: 4 June 2019 Revised: 5 December 2019 Accepted: 12 December 2019

Published online: 17 February 2020 
molecular mechanism of paraptosis is not well elucidated, studies have revealed that paraptosis is independent of the caspase signaling cascade and may involve activation of the mitogenactivated protein kinase (MAPK) pathway $[15,16]$. The ER stress markers Bip and Chop were found to be elevated in paraptosis $[17,18]$.

In this study, we tested the potential antitumor and radiosensitizing activities of CMR in NSCLC cells. Our results showed that CMR increased clonogenic cell death by inducing paraptosis in NSCLC cells in response to radiotherapy, with characterized cytoplasmic vacuolation and dilated ER triggering ER stress.

\section{MATERIALS AND METHODS}

Chemicals and cell lines

CMR was provided by Jingkui Tian's lab [19] at the Key Laboratory of Biomedical Engineering of Zhejiang University; it had a purity $\geq 98 \%$ as determined by high-performance liquid chromatography (HPLC). CMR stock solutions were dissolved in dimethyl sulfoxide (DMSO) and diluted to the required concentrations before use. U0126 (PHZ1283, Thermo Fisher, MA, USA) was used to inhibit the MAPK pathway. The H460 (human large cell lung cancer), A549 and PC-9 cell lines (human lung adenocarcinoma) were obtained from American Type Culture Collection. Cells were grown in RPMI1640 medium supplemented with $10 \%$ fetal bovine serum (FBS), $100 \mathrm{IU} / \mathrm{mL}$ penicillin and $100 \mu \mathrm{g} / \mathrm{mL}$ streptomycin and were maintained at $37{ }^{\circ} \mathrm{C}$ in $5 \% \mathrm{CO}_{2}$ in a humidified incubator. The cells were passaged twice a week and used in the exponential growth phase.

\section{Cell viability assays}

Cell viability was determined by the CCK- 8 assay. Briefly, cells were plated into 96-well plates at $\sim 5000$ cells per well until cell adhesion. CMR was added to the medium at the indicated concentration. After incubation with CMR for 24,48 and $72 \mathrm{~h}$, each well was incubated with $10 \mu \mathrm{L}$ of CCK-8 solution per $100 \mu \mathrm{L}$ of medium for $1 \mathrm{~h}$ away from light. The absorbance of each well was measured at $450 \mathrm{~nm}$ by using a multimode detection platform (Molecular Devices, CA, USA) according to the instructions of the CCK-8 assay kit.

\section{Clonogenic survival assays}

Cells in log phase were plated in six-well plates and pretreated with CMR at the indicated concentrations or with DMSO as controls. IR treatment was delivered $2 \mathrm{~h}$ later. Irradiated cells were then maintained in culture medium for 14 days. Colonies greater than 50 cells were counted as positive surviving colonies, and the number of colonies was normalized to that in the controls. Mean inactivation doses were determined as previously reported by the Fertil method [20], and the sensitizer enhancement ratio (SER) of CMR treatment was calculated as the ratio of mean inactivation dose $_{\text {control }} /$ mean inactivation dose CMR-treated. $_{\text {. }}$

Median effect analysis

Cells were treated with a constant ratio of doses of IR and CMR based on the corresponding lethal doses (LD) $L D_{50}$, and cell survival was determined by clonogenic survival assay. A plot of the log of the total dose versus the log of the reciprocal of the fraction of cells affected minus 1 yielded a linear plot. The slopes and $y$ intercepts of the plots were used to calculate the combination index $(\mathrm{Cl})$ with CalcuSyn Version 2.0 software (BioSoft, Cambridge, UK). The $\mathrm{Cl}$ values were interpreted as follows: $<1.0=$ synergism; $0=$ additive; and $>1.0=$ antagonism.

\section{siRNA transfection}

For Bip siRNA treatment, cells were transiently transfected with siRNA-scramble and siRNA-Bip (Guannan Biotech, Hangzhou, China). The siRNA sequences are as follows: siRNA-1: $5^{\prime}$-GAAAUCG
AAAGGAUGGUUAAU-3'; siRNA-2: 5'-GGAGCGCAUUGAUACUAGA-3'; siRNA-3: 5'-CAGAUGAAGCUGUAGCGUA-3'; and scramble siRNA: 5'-UUCUCCGAACGUGUCACGU-3'. Forty-eight hours after siRNA transfection, the cells were treated with CMR for survival analysis and calreticulin staining.

Immunofluorescent imaging

Confocal microscopy was used to visualize the formation of cytoplasmic vacuoles in H460 cells. Cells were treated with $6 \mu \mathrm{M}$ CMR for $48 \mathrm{~h}$, followed by irradiation or no IR as a control. After treatment, the cells were washed twice with PBS and then fixed with $4 \%$ paraformaldehyde for $30 \mathrm{~min}$. Triton X-100 (0.5\%) was used to permeabilize the cells for $8-10 \mathrm{~min}$ at room temperature, and the cells were blocked with $1 \%$ BSA in PBS for 10 min. After washing with PBS, the cells were stained with the ER marker calreticulin (Cell Signaling Technology, Danvers, MA, USA) and the nuclear dye DAPI (Dako, Denmark). Immunofluorescent images were acquired using a Leica DMi 8 confocal microscope (Leica Microsystems, German). At least 100 cells from each experiment were counted at random to calculate the percentage of cells as "positive" if they displayed vacuoles. The results from at least three different experiments were averaged.

\section{Transmission electron microscopy}

After CMR treatment, cells were fixed in $2.5 \%$ glutaraldehyde for $4 \mathrm{~h}$ and washed in $0.1 \mathrm{M}$ phosphate buffer three times. The samples were immersed in $1 \%$ osmium tetroxide for $1 \mathrm{~h}$, and $2 \%$ uranyl acetate was used for sample dyeing for $30 \mathrm{~min}$. Then, the cells were dehydrated by a graded ethanol series for $10 \mathrm{~min}$ and $100 \%$ acetone twice. The processed cells were embedded in embedding medium for $2 \mathrm{~h}$ and heated at $60^{\circ} \mathrm{C}$ for polymerization. The ultrathin sections were obtained by cutting in a microtome. After staining with uranyl acetate and lead citrate, the sections were examined under a transmission electron microscope (Hitachi, Ibaraki, Japan) at $80 \mathrm{kV}$ of accelerating voltage.

\section{Annexin V-FITC/PI assay}

Apoptosis was examined using an Annexin V-FITC apoptosis detection kit (BD Biosciences, NJ, USA). Cells were prepared according to the manufacturer's instructions. Briefly, $1 \times 10^{6}$ cells were harvested, washed twice with cold PBS and stained with Annexin V-FITC and PI in $1 \times$ binding buffer before flow cytomety (FCM) analysis. The populations of apoptotic cells were determined using a Becton Dickinson FACSCanto II. Both early apoptotic (Annexin V-positive and PI-negative) and late apoptotic (Annexin V-positive and PI-positive) cells were included in determining total apoptosis.

\section{Western blot analysis}

Cells were collected and washed twice with precooled PBS. Cells were then lysed in RIPA buffer containing protease and phosphatase inhibitors (Thermo Scientific, MA, USA). Twenty microliters of lysates were used for Western blot analyses using antibodies against phospho-p38, total-p38, phospho-Erk, total-Erk, phospho-JNK, total-JNK, Chop, Bip, PARP, Caspase 3 and $\beta$-Actin (Cell Signaling Technology, Danvers, MA, USA). The Western blot signals were detected by BioRad ChemiDoc XRS+ (Biorad, CA, USA) using a chemiluminescence kit.

\section{In vivo study}

$\mathrm{H} 460$ cells $\left(5 \times 10^{6}\right.$ in $0.2 \mathrm{~mL}$ of $\left.1 \times \mathrm{HBSS}+1 \% \mathrm{HSA}\right)$ were inoculated subcutaneously into the right thighs of female $\mathrm{Nu} / \mathrm{Nu}$ mice (5-7 weeks of age, Charles River, Beijing, China). The mice were randomized into four groups when the average tumor volume reached $200 \mathrm{~mm}^{3}$. The following treatments were given: (a) methylcellulose/Tween 80 as a vehicle; (b) CMR (50 mg/kg every day) on days 1-7 by intraperitoneal injection; (c) IR (10 Gy) on day 1; and (d) CMR + IR (10 Gy). Tumors were measured twice a week, 
and tumor volumes were determined from caliper measurements of the tumor length $(L)$ and width $(W)$ and calculated according to the formula $\left(L \times W^{2}\right) / 2$. Tumor growth inhibition (TGI) and antitumor efficacy were determined by using the following equation: $[\% \mathrm{TGI}=(1-$ change in tumor volume in treatment group/change in tumor volume in control group) $\times 100]$.

\section{Immunohistochemistry analysis}

$\mathrm{H} 460$ xenograft tumors were collected 10 days after the treatment began. The tissue samples were fixed in $10 \%$ formaldehyde solution, embedded in paraffin and sliced into 5 - $\mu \mathrm{m}$ sections. Antigen retrieval was conducted on formalin-fixed paraffinembedded (FFPE) tissue sections incubated in retrieval buffer for 5 min (Dako, Denmark). Tissue samples were then incubated with an endogenous peroxidase blocker for $10 \mathrm{~min}$ and then incubated with primary antibodies (CC3, Cell Signaling Technology, Danvers, MA, USA) for $60 \mathrm{~min}$ at room temperature. DAKO EnVision ${ }^{\mathrm{TM}}+$ System-HRP was used as a secondary antibody (Dako, Denmark). Tumor sections were incubated with biotinylated primary antibody (Dako, Denmark) for Ki67 immunohistochemical analysis. Quantification of Ki67- and CC3-positive signals was conducted using the Ariol system (Genetix, San Jose, CA, USA).

\section{Statistical analysis}

Data are presented as the means \pm SD. Student's $t$ test was used to determine the significance between groups. Significance was defined at the level of $P<0.05$.

\section{RESULTS}

CMR inhibits cancer cell proliferation and induces cytoplasmic vacuolation in lung cancer cells

The anticancer effect of CMR (molecular weight: 648.69) was evaluated in H460, A549 and PC-9 cells. These cells were treated with CMR $(0,2,4,8,16$ and $32 \mu \mathrm{M})$ for 24,48 and $72 \mathrm{~h}$, and cell viability was then determined. We found that exposure to CMR obviously decreased the viability of H460, A549 and PC-9 cells in a dose-dependent manner, suggesting that CMR has cytotoxic activity against lung cancer cells. The $\mathrm{IC}_{50}$ values of CMR in $\mathrm{H} 460$, A549 and PC-9 cells were $10.8,10.1$ and $12.3 \mu \mathrm{M}$ at $24 \mathrm{~h} ; 6.1,6.3$ and $8.9 \mu \mathrm{M}$ at $48 \mathrm{~h}$; and $4.8,5.7$ and $7.9 \mu \mathrm{M}$ at $72 \mathrm{~h}$, respectively (Fig. 1a). Microscopic observation showed that CMR treatment induced extensive cytoplasmic vacuolation in H460, A549 and PC9 cells. A significantly higher percentage of cytoplasmic vacuolated cells $(36.6 \% \pm 3.4 \%$ in $\mathrm{H} 460$ cells, $33.4 \% \pm 3.0 \%$ in A549 cells and $24.5 \% \pm 4.1 \%$ in PC-9 cells) was observed when cells were treated with $6 \mu \mathrm{M}$ CMR compared to that of control cells or cells that were treated with lower doses of CMR (Fig. 1b).

Low and medium doses of CMR caused paraptosis but not apoptosis

It has been reported that cytoplasmic vacuolation induced by paraptosis is due to ER stress $[16,21]$. As shown in Fig. 2a, immunofluorescent staining showed that the edges of all cytoplasmic vacuoles in CMR-treated cells were stained with the ER marker calreticulin (red color), indicating that the formation of vacuoles originated from ER dilation. We also noticed that the percentage of cytoplasmic vacuoles formed in these CMR-treated cells increased in a dose-dependent manner.

We used transmission electron microscopy (TEM) to determine the potential ultrastructural changes in $\mathrm{H} 460$ and A549 cells in response to CMR treatment. We found that after $48 \mathrm{~h}$ of treatment with $6 \mu \mathrm{M} C M R$, empty vacuoles with no visible materials observed inside the vacuoles had formed. Swollen ER cisternae also occurred. However, we did not observe DNA fragmentation or chromatin condensation in the nuclei of lung cancer cells after CMR treatment (Fig. 2b). In addition, Annexin V-FITC analysis showed that CMR treatment did not induce significant apoptosis in $\mathrm{H} 460$ and A549 cells, although slight increases in apoptotic cell death were detected in both cell lines when the cells were treated with $8 \mu \mathrm{M}$ of CMR for $48 \mathrm{~h}$ (Fig. 2c).

CMR caused ER stress-dependent paraptosis of lung cancer cells We next analyzed the protein expression levels of the ER stress markers Bip and Chop in lung cancer cells following treatment with CMR. We found that the expression of Bip and Chop proteins significantly increased in parallel with increasing doses of CMR in H460 and A549 cells. However, we did not detect any obvious changes in the protein expression of ALG-2-interacting protein $X$ (Alix), which is an inhibitor of paraptosis [15], or the autophagyspecific marker LC3B. We also determined the changes in protein expression of three other ER transmembrane sensors, inositol requiring enzyme 1 (IRE1), protein kinase RNA (PKR)-like ER kinase (PERK) and activating transcription factor 6 (ATF6), and our results showed that the expression of IRE1, p-PERK and ATF6 increased in $\mathrm{H} 460$ cells when the cells were treated with $6 \mu \mathrm{M}$ CMR. In A549 cells, however, we detected increased protein expression of IRE1 but not p-PERK or ATF6 in CMR-treated cells. On the other hand, we did not detect any changes in apoptosis-related caspase-3 (neither the full-length protein nor cleaved fragments) or its substrate PARP in $\mathrm{H} 460$ and A549 cells after CMR treatment (Fig. 3a). Taken together, these results suggest that exposure to low and medium concentrations of CMR induces paraptosis but not apoptosis in NSCLC cells.

These observed changes in ER stress proteins indicate a potential involvement of ER stress in the paraptosis process of cells treated with CMR. We thus evaluated the role of an ER stress protein on CMR-induced paraptosis in $\mathrm{H} 460$ cells. We found that knocking down Bip by siRNA transfection (Fig. 3b) not only decreased the cell-killing effect of CMR treatment (Fig. 3c) but also reduced the percentage of cytoplasmic vacuoles (Fig. $3 \mathrm{~d}$ ) in $\mathrm{H} 460$ cells. Therefore, we suggest that CMR exposure induces paraptosis through modulation of ER stress proteins.

CMR radiosensitizes lung cancer cells mainly through enhancing paraptosis

We further evaluated the potential radiosensitization effects of CMR on H460 and A549 cells. For this, we performed a clone formation assay to determine the SER. The cells were pretreated with $0,2,4$ or $6 \mu \mathrm{M} C M R$ and then irradiated with different doses of IR. We found that pretreatment with CMR enhanced the sensitivity of cells to radiotherapy, and the SER values reached 1.35 for $\mathrm{H} 460$ cells and 1.28 for A549 cells at a CMR dose of $6 \mu \mathrm{M}, 1.14$ for $\mathrm{H} 460$ cells and 1.19 for A549 cells at a dose of $4 \mu \mathrm{M}$, and 1.12 for H460 cells and 1.10 for A549 cells at a CMR dose of $2 \mu \mathrm{M}$ (Fig. 4a). We also determined the $\mathrm{Cl}$ for CMR combined with IR in $\mathrm{H} 460$ and A549 cells by treating the cells with constant ratios of corresponding $\mathrm{LD}_{50}$ of $\mathrm{CMR}$ and IR. Our results showed that combination treatment with IR and CMR led to an overall $\mathrm{Cl}$ value of $<1.0$, indicating a synergistic radiosensitization effect of CMR on H460 cells (Fig. 4b). Apoptosis analysis further showed that, while the percentage of apoptotic cells increased in a dose-dependent manner in cells in response to IR treatment, pretreatment with CMR had no effect on the apoptotic response to IR in $\mathrm{H} 460$ or A549 cells ( $P>0.05$, Fig. 4c). However, we detected dramatically increased cell populations with vacuole formation in irradiated $\mathrm{H} 460$ cells (from $23.5 \%$ to $42.2 \%$ ) and A549 cells (from $18.1 \%$ to $33.8 \%$ ) when cells were pretreated with CMR. Notably, no such change was observed in irradiated control cells that were not cotreated with CMR (Fig. 4d). Consistent with the above observations, Western blot analysis showed that the expression of Bip and Chop proteins increased only in the cells treated with the combination of CMR and IR. In addition, we also noticed that when cells were pretreated with $6 \mu \mathrm{M} \mathrm{CMR}$, the protein levels of IRE1 and ATF6 and the phosphorylation level of PERK ( $p$-PERK) increased in $\mathrm{H} 460$ cells in response to IR exposure. However, in 
a

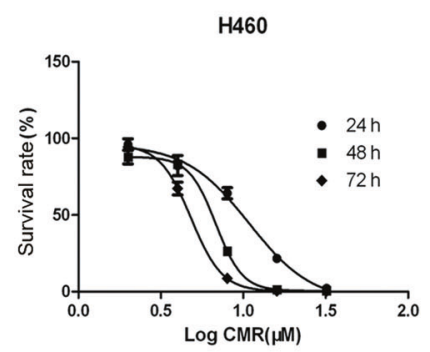

b
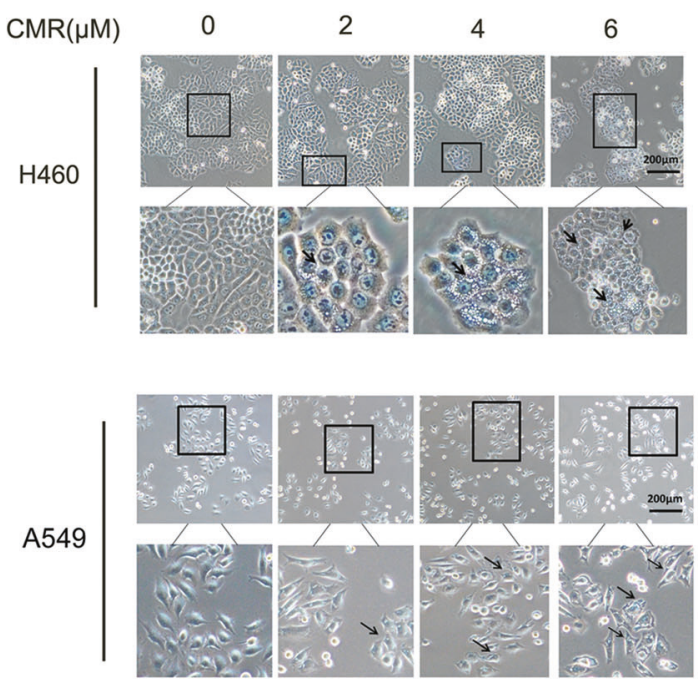

PC-9
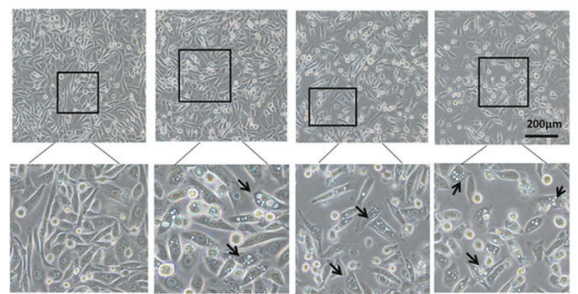
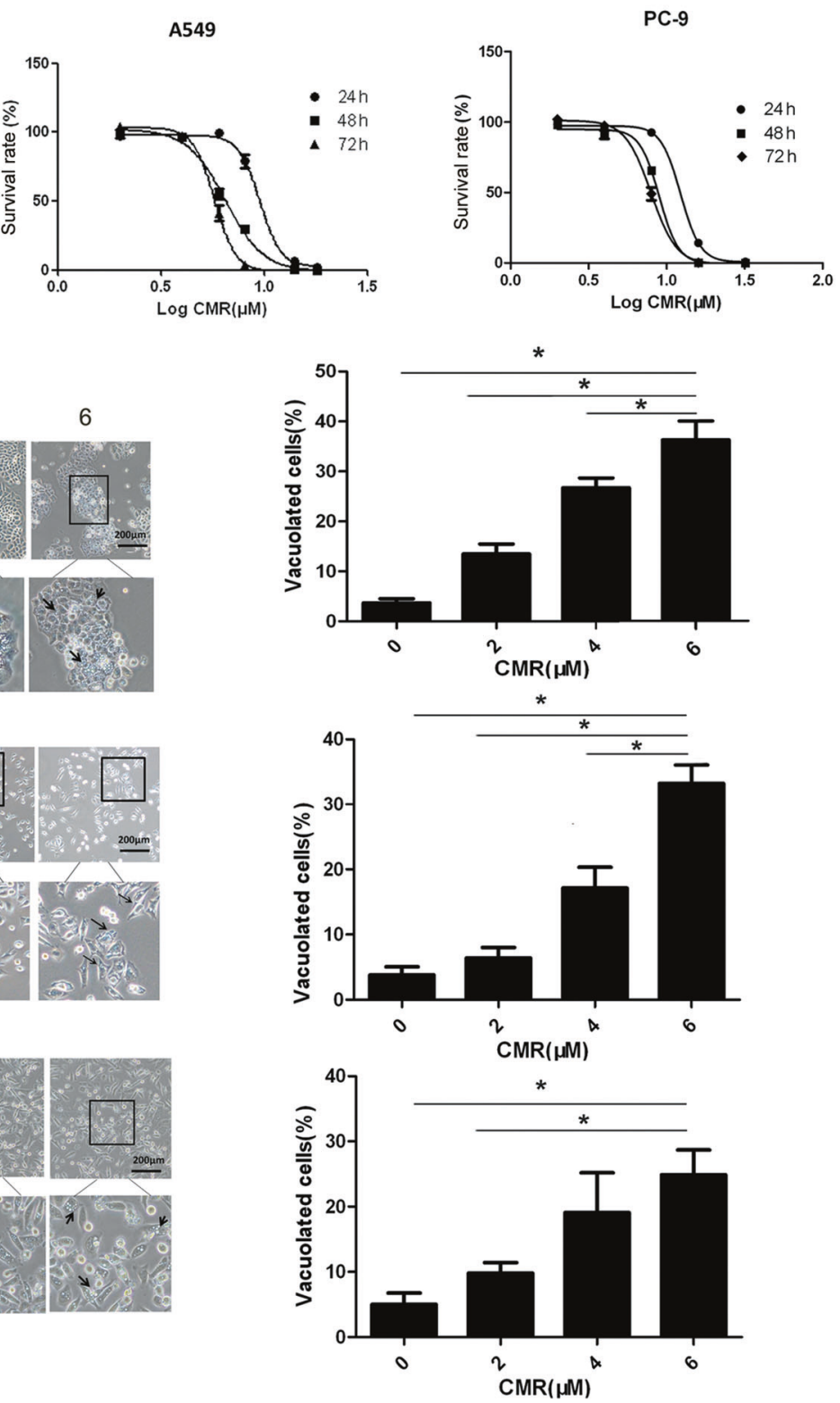

Fig. 1 CMR inhibited cell viability and induced cytoplasmic vacuolization in lung cancer cells. a Cells were treated with CMR at the indicated concentrations, and cell viability was determined using a CCK-8 assay. Data represent the average of three experiments. Error bars indicate standard deviation. b Phase-contrast images of H460, A549 and PC-9 cells following incubation with CMR at the indicated concentrations for $48 \mathrm{~h}$ and the percentage of CMR-induced cytoplasmic vacuolation in H460, A549 and PC-9 cells; * indicates statistical significance.

A549 cells, only IRE1 protein levels obviously increased in cells that were cotreated with CMR and IR (Fig. 4e).

MAPK activation mediates paraptosis induced by CMR To understand the detailed mechanism by which CMR treatment induces paraptosis in NSCLC cells, we analyzed the signal activation of the p38/Erk/JNK MAPK pathway in cells treated with IR CMR, individually or in combination. Western blot analysis revealed that treatment with $I R$ or CMR alone upregulated the phosphorylation levels of ERK, JNK and p38 in H460 cells compared to those of the control cells. Of note, the most significant change in these phosphorylation events was observed in cells treated with the combination of IR and CMR (Fig. 5a). Adding the MAPK pathway inhibitor U0126, which markedly blocked the basal level of the phosphorylation of ERK proteins, to the culture medium of $\mathrm{H} 460$ cells before treatment with IR, CMR or the combination, blocked the basal protein expression and increase in Bip and Chop proteins in response to the cotreatment with IR and CMR (Fig. 5b), and it also decreased the percentage of vacuolated cells in response to CMR alone (from $23.2 \% \pm 2.1 \%$ to $11.8 \% \pm 3.5 \%$ ) or CMR combined with IR (from $41.3 \% \pm 6.0 \%$ to $25.2 \% \pm 4.1 \%$, Fig. $5 \mathrm{c}$ ).

The combination of CMR and radiation therapy inhibits tumor growth in $\mathrm{H} 460$ xenografts

We further extended our study to an in vivo model. In this experiment, $\mathrm{H} 460$ cells were inoculated into $\mathrm{Nu} / \mathrm{Nu}$ mice to establish xenografts, and the effects of CMR, IR or CMR combined with IR on tumor growth were assessed. Our results showed that treatment with a single dose of IR (10 Gy) or daily oral treatment 
a
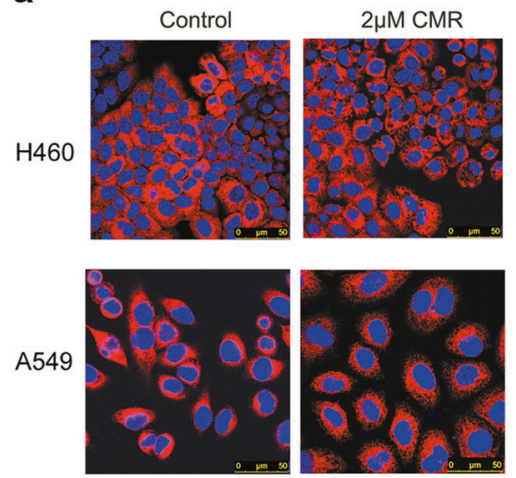

$6 \mu \mathrm{M}$ CMR
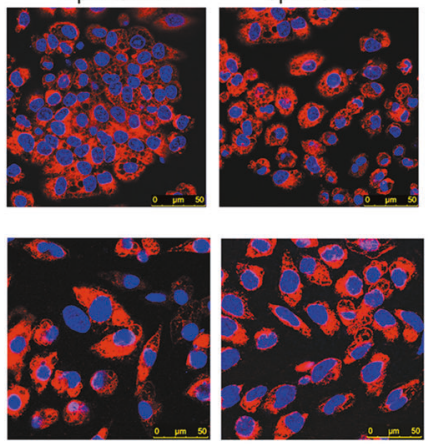
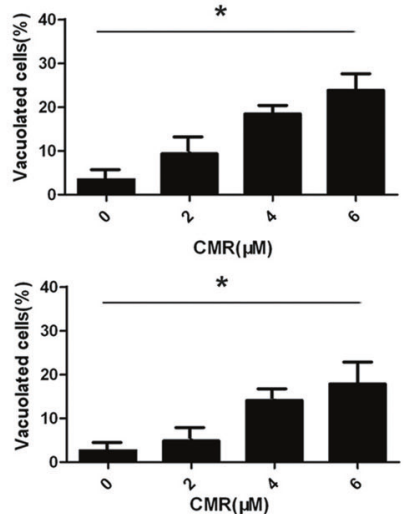

b

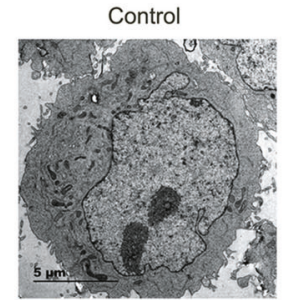

$\mathrm{H} 460$

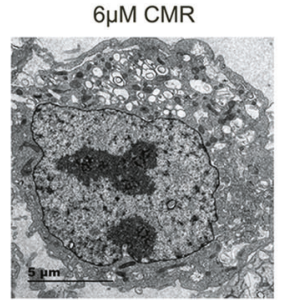

A549

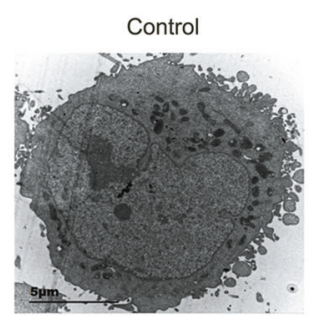

C
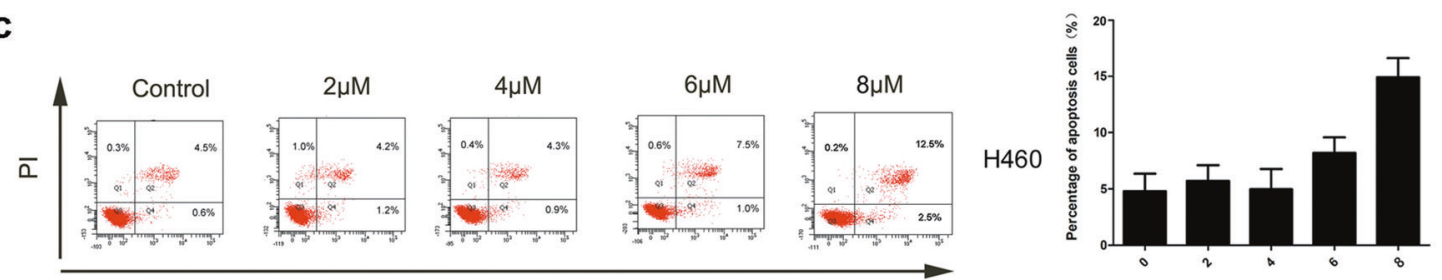

$\overline{\mathrm{L}}$
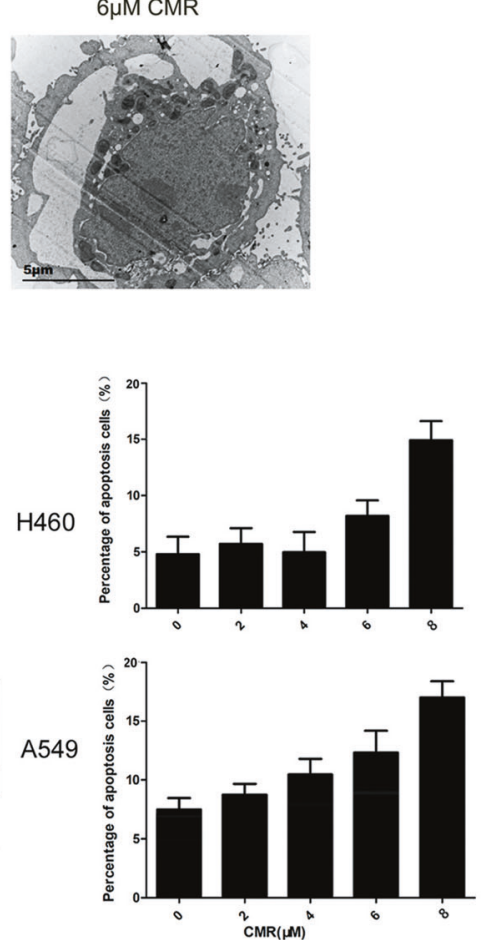

Fig. 2 Effects of CMR on paraptosis of lung cancer cells without an apoptotic response. a The cytoplasmic vacuolation induced in H460 and A549 cells was observed by immunofluorescence staining with calreticulin antibody, and the cells with obvious cytoplasmic vacuolation were counted as positive cells. At least 100 cells from each experiment were counted at random to calculate the percentage of positive cells. The scale bar represents $50 \mu \mathrm{m}$, and all images are at the same magnification; * indicates statistical significance. b Transmission electron microscopy of lung cancer cells treated with CMR. The scale bar represents $5 \mu \mathrm{m}$, and all images are at the same magnification. c Apoptosis analysis. Cells were treated with CMR $(0,2,4,6$ and $8 \mu \mathrm{M})$ for $48 \mathrm{~h}$ and analyzed by flow cytometry.

with CMR (50 mg/kg for 7 days) inhibited in vivo H460 tumor growth with TGI of $36.7 \%$ and $76.4 \%$, respectively. Interestingly, we noticed that the combination treatment of IR and CMR caused significantly enhanced tumor growth inhibition up to $95.7 \%$ (Fig. 6a). The tolerability analysis measured mouse body weight and showed that treatments with CMR or CMR combined with IR did not cause obvious body weight changes during the experiment, suggesting that treatment with IR combined with CMR was well tolerated (Fig. S1).

Western blot analysis showed that CMR treatment or the combination treatment led to an upregulation of Bip and Chop and activation of $p$-Erk in xenograft tumor tissues (Fig. 6b). We also noticed that, although treatment with IR or CMR alone reduced $\mathrm{Ki} 67$ staining in $\mathrm{H} 460$ xenograft tumors, combination treatment further decreased the level of Ki67 staining in tumor cells. Exposure to CMR, however, did not increase the IR-induced positive staining of cleaved caspase 3 (CC3) in the tumor tissues (Fig. 6c and Table S1).

\section{DISCUSSION}

Radiation therapy is an important component of cancer treatment, and more than $50 \%$ of cancer patients will receive radiotherapy during clinical management of the disease. Radiotherapy also contributes to $40 \%$ of the curative treatments for cancer patients. For NSCLC patients, concurrent chemotherapy and radiation therapy is the standard care for local advanced patients; however, the clinical outcomes remain unsatisfactory, with a median 
a $\begin{array}{ll}\text { A549 } \\ 0 & 2\end{array}$

$\begin{array}{llll}0 & 2 & 4 & 6\end{array}$
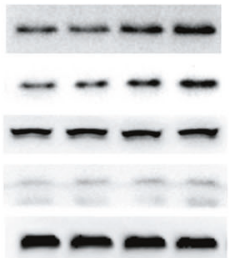

P-PERK

IRE1

ATF6

B-Actin

b

Bip

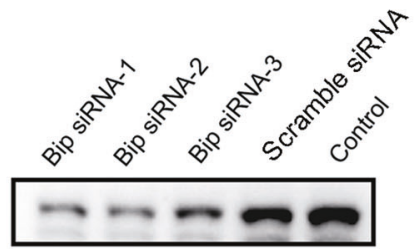

$\beta$-Actin

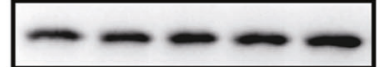

Bip
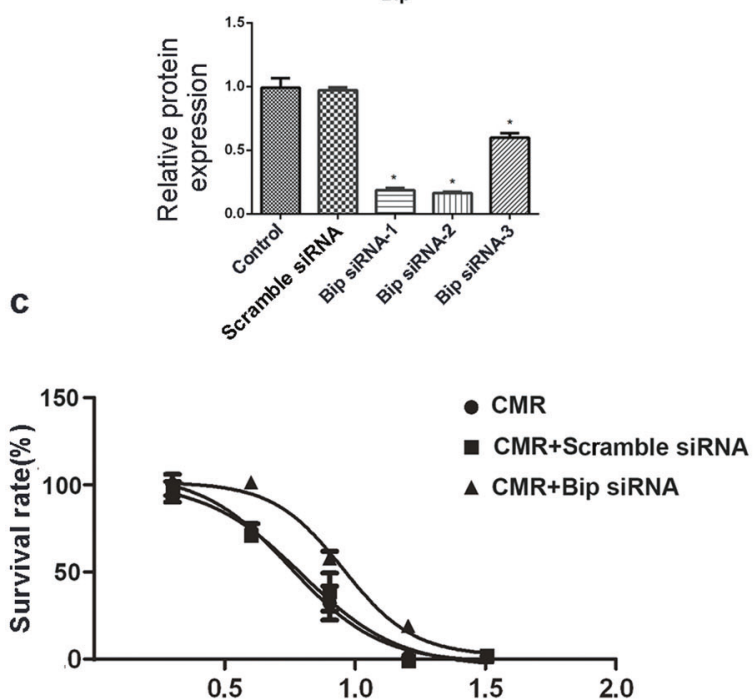

c

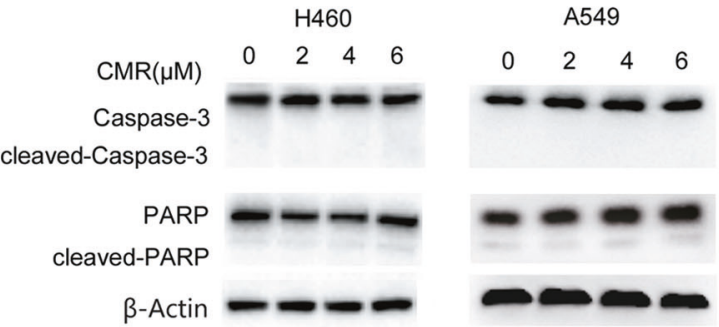

d

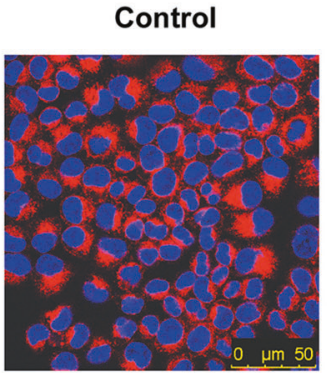

CMR
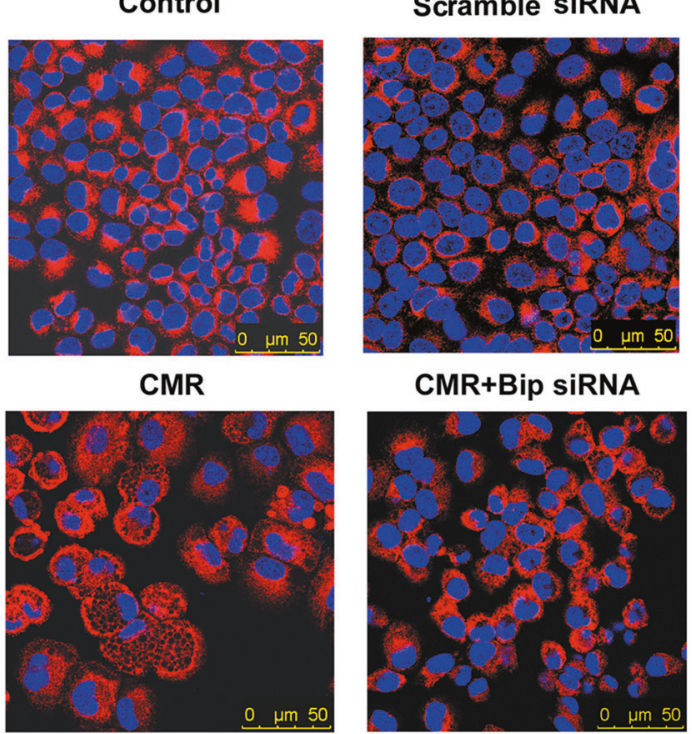

CMR+Bip siRNA

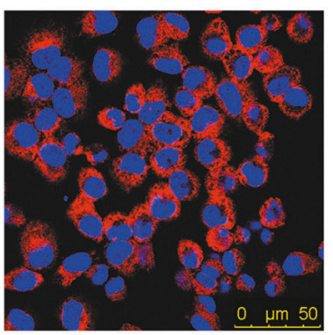

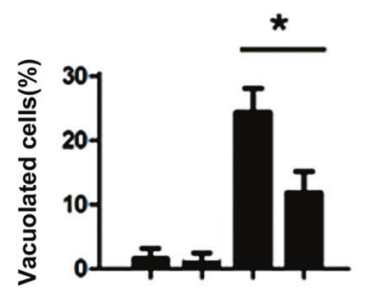

Fig. 3 Effects of CMR on paraptosis depend on endoplasmic reticulum stress. a Total cell lysates were collected and analyzed for Bip, Chop, Alix, LC3B, p-PERK, IRE1, ATF6, caspase 3 and PARP proteins. Anti- $\beta$-actin antibody was included as a loading control. Cells were treated with CMR $(0,2,4$ or $6 \mu \mathrm{M})$ for $48 \mathrm{~h}$. b H460 cells were transiently transfected with Bip siRNA or scramble-siRNA as a control. Western blot analysis showed the inhibitory effect of siRNA on Bip protein in cells collected $72 \mathrm{~h}$ after transfection. Bip-siRNA-2 was selected for Bip knockdown in the CCK-8 and immunofluorescence staining assays; * indicates statistical significance. c A CCK-8 assay was performed on siRNA-transfected cells treated with CMR as described above. d Immunofluorescence staining of siRNA-transfected cells treated with CMR. The scale bar represents $50 \mu \mathrm{m}$, and all images are at the same magnification.

progression-free survival of 5-6 months. Recently, a multicenter, open-labeled, randomized phase II trial showed that targeted therapy with an EGFR inhibitor combined with radiation provides a statistically significant PFS improvement (23.4 vs. 9.0 months) compared to that of chemotherapy plus radiotherapy in unresectable stage III NSCLC with an activating EGFR mutation, indicating that lung cancer patients with an EGFR mutation can benefit from this new therapeutic strategy [22], although nearly
$60 \%$ of NSCLC patients cannot benefit from this treatment because patients have tumors that do not harbor an EGFR mutation. However, the success of the combination of IR with EGFR-targeting chemotherapy suggests the clinical potential of developing a novel radiotherapeutic strategy for NSCLC patients.

Studies have revealed that natural products can sensitize cancer cells to radiation therapy $[23,24]$. The mechanisms by which the natural components synergize with IR to facilitate cancer cell 
a

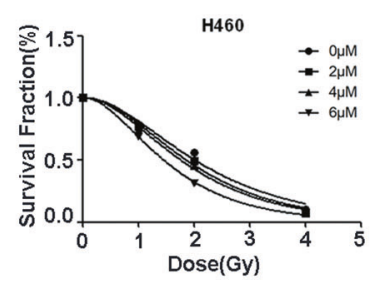

b

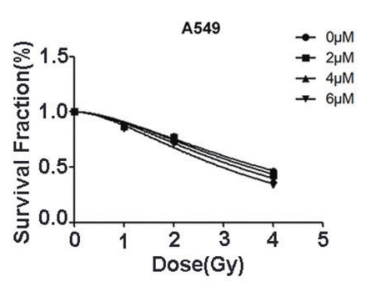

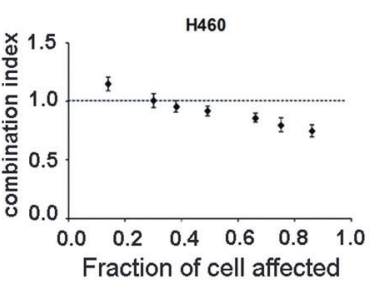

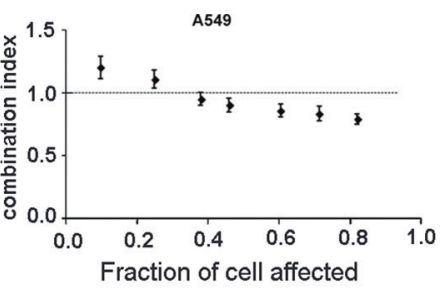

C
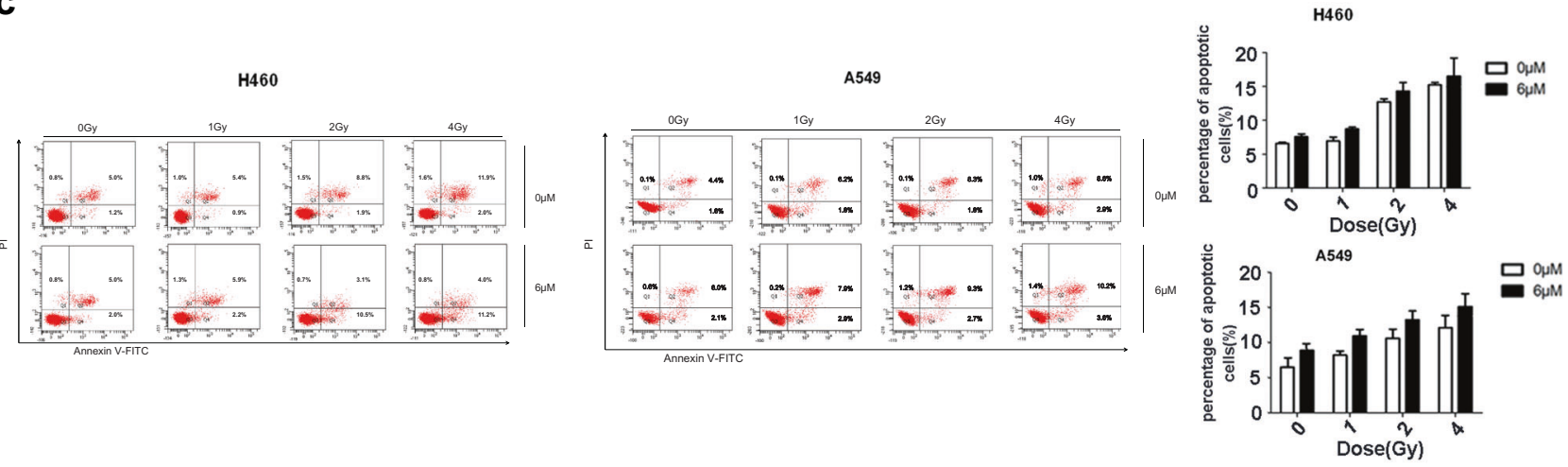

d

H460

OGy

1Gy

2Gy

4Gy

A549

OGy

1Gy

$2 G y$

4Gy
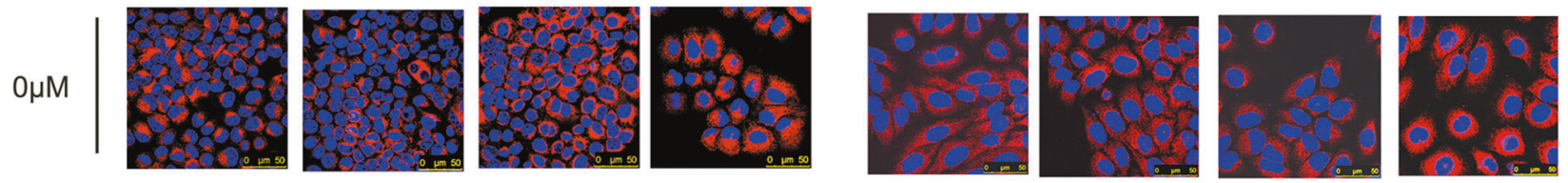

$6 \mu \mathrm{M}$
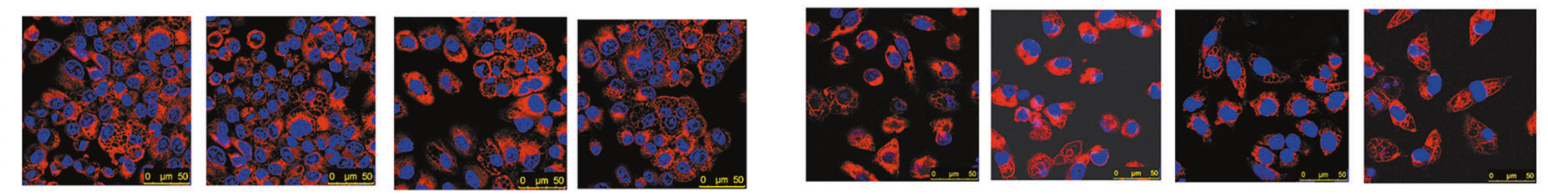

$\mathrm{H} 460$
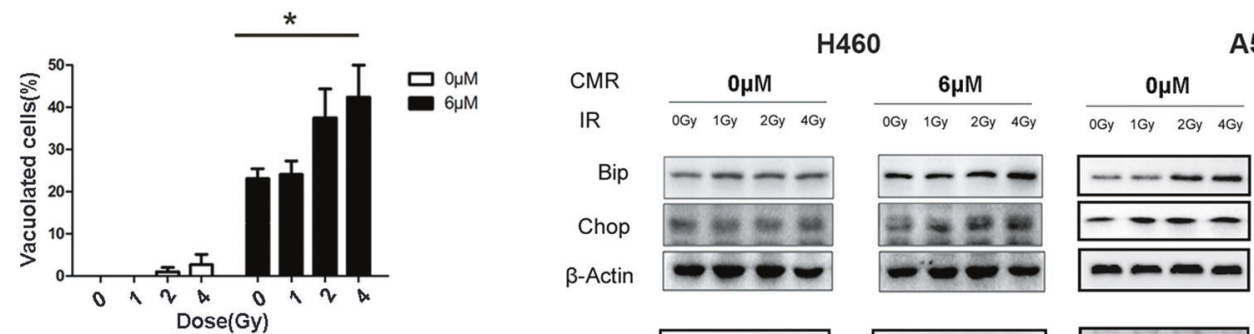

A549

A549
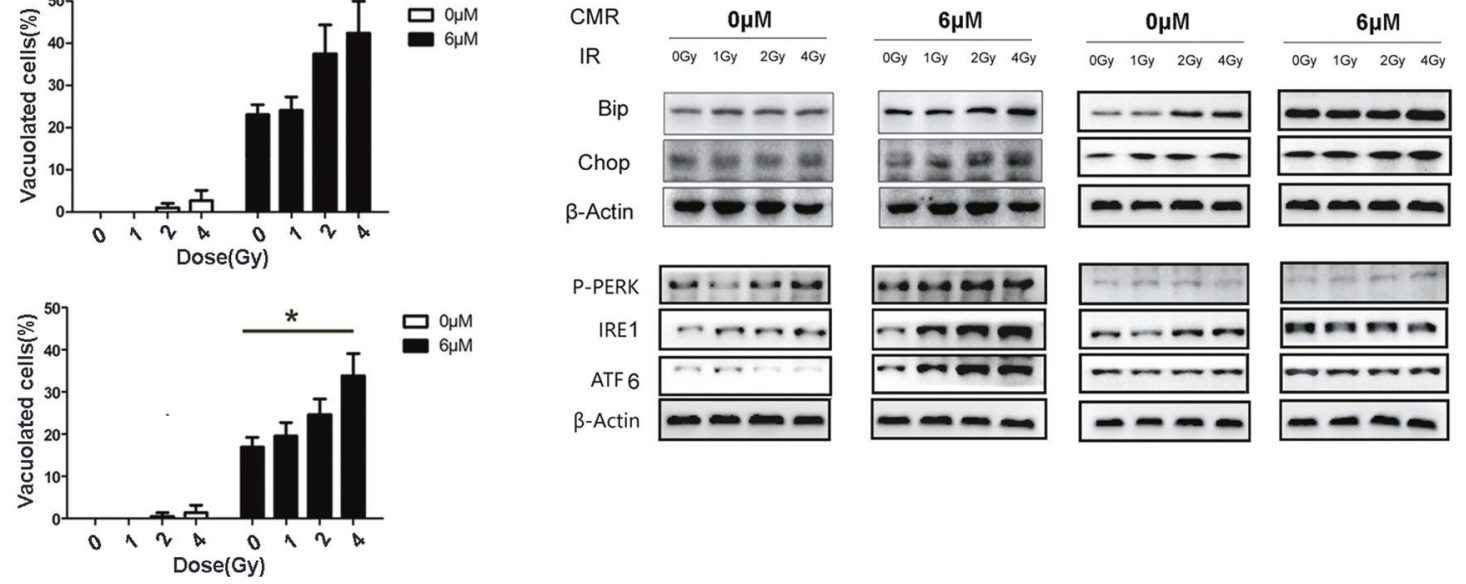

Fig. 4 CMR radiosensitizes lung cancer cells by enhancing paraptosis. a H460 and A549 cells were pretreated with $6 \mu \mathrm{M}$ CMR for $2 \mathrm{~h}$ and then irradiated with the indicated doses. Clonogenic survival assays were performed as described in the Materials and Methods. Data represent the average of three experiments. b The Cl was determined in $\mathrm{H} 460$ and A549 cells treated with IR and CMR. c Apoptotic analysis was conducted $48 \mathrm{~h}$ after treatment by flow cytometry. d Cytoplasmic vacuolation induced in $\mathrm{H} 460$ and A549 cells was observed by immunocytochemistry: * indicates statistical significance. The scale bar represents $50 \mu \mathrm{m}$, and all images are the same magnification. e Cell lysates were collected $48 \mathrm{~h}$ after radiation and analyzed for Bip, Chop, p-PERK, IRE1 and ATF6 proteins. Cells were treated with $6 \mu \mathrm{M}$ CMR followed by radiation with $0,1,2$ or $4 \mathrm{~Gy}$. 
a

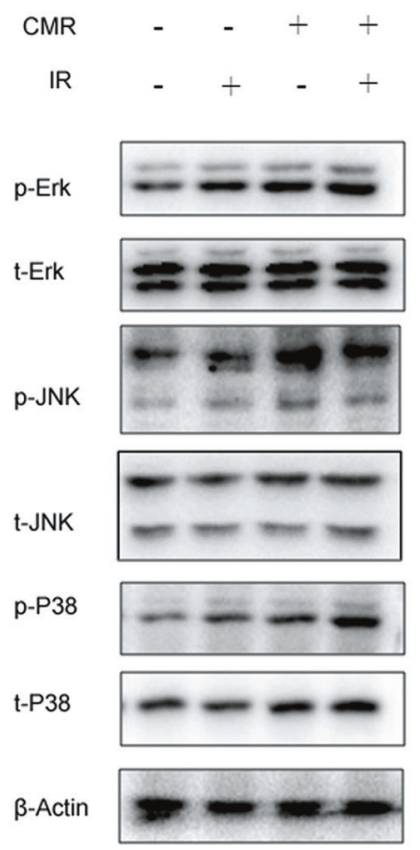

b

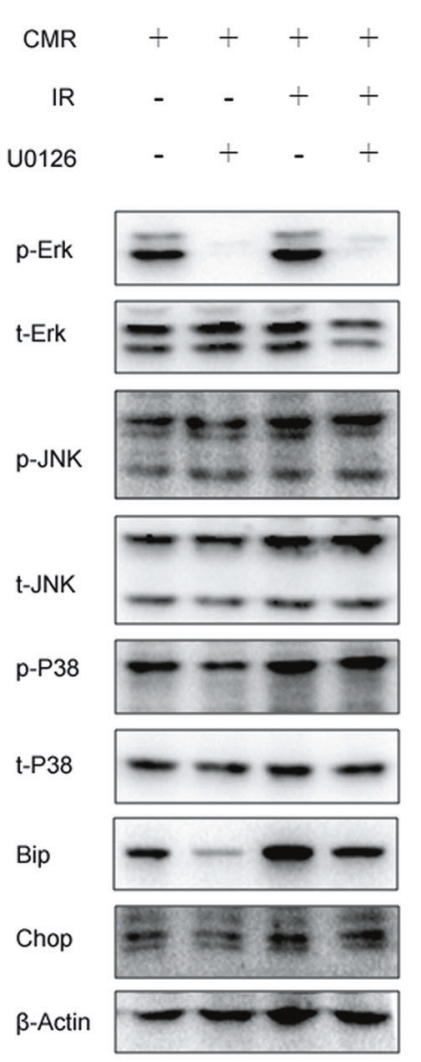

C
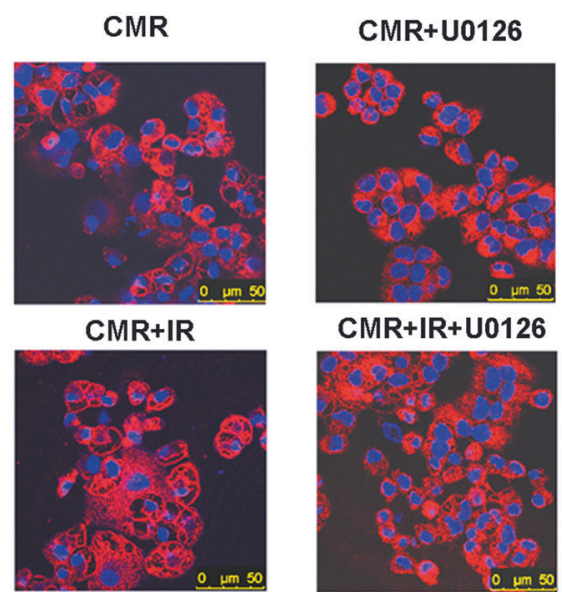

CMR+IR+U0126

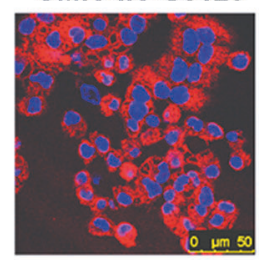

*

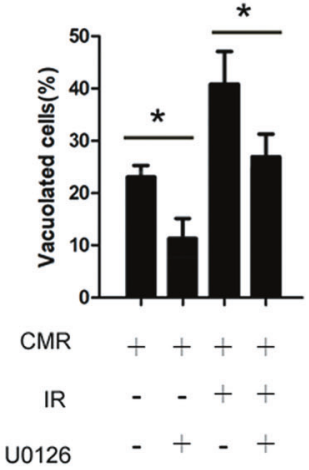

Fig. 5 MAPK activation mediates CMR-induced paraptosis. a Total cell lysates were collected from H460 cells after the indicated treatments and analyzed for phosphorylation and total Erk, JNK and p38 proteins. Anti- $\beta$-actin antibody was included as a loading control. $\mathbf{b} \mathrm{H} 460$ cells were treated with CMR and radiation, with or without U0126. Cell lysates were collected and analyzed for phosphorylation and total Erk, JNK and p38 protein, as well as Chop and Bip. c Cytoplasmic vacuolation induced in H460 cells with the indicated treatments was observed by immunocytochemistry; * indicates statistical significance. The scale bar represents $50 \mu \mathrm{m}$, and all images are at the same magnification.

killing are usually by enhancing apoptosis, affecting the cell cycle, and/or attenuating angiogenesis [25-29]. In this study, we demonstrated that CMR, a type of Diels-Alder adduct from Mulberry leaves, enhances the radiosensitivity of NSCLC cells by inducing paraptosis. Previous studies have shown the anticancer activity of CMR in various human cancer cell lines, but little is known about its effects on lung cancer. Our current data showed that CMR significantly induced cell killing. Of interest, we found that CMR treatment induced ER dilation and cytoplasmic vacuolation in NSCLC H460 cells. Immunofluorescence analysis and TEM imaging further showed that in CMR-treated cells, the ER underwent swelling and fusion. In addition, CMR treatment enhanced the expression of ER stress markers, including the transcription factors Bip and Chop. This evidence indicates that CMR kills cancer cells through paraptosis. However, we noticed that CMR treatment did not cause activation of caspase- 3 and PARP, which indicates that apoptosis is not a cause of CMRinduced cell death in these cancer cells. In the combination treatment experiment, we also demonstrated that the synergistic effect of CMR on IR-induced cell killing in NSCLC cells involved paraptosis but not apoptosis. Thus, CMR treatment triggers paraptosis in NSCLC cells, which results in significant cancer cell death and a synergistic cell-killing effect of cells in response to IR. Of note, however, we noticed that the expression of all three ER transmembrane sensors, IRE1, PERK and ATF6, was enhanced in CMR-treated H460 cells, while only IRE1 protein expression was increased in A549 cells, indicating the potential of different ER sensors to be induced by ER stress in distinct lung cancer cells [30].
Paraptosis is a nonapoptotic pathway whose main features are extensive cytoplasmic vacuolation and the absence of significant cell membrane blebbing and nuclear shrinkage. Paraptosis is a molecular pathway that is independent of caspases, and although studies have not fully explored the detailed molecular mechanism of paraptosis, it is proposed that the MAPK pathway may also participate in the development and the process of paraptosis $[15,31,32]$.

We also found in our study that CMR treatment activated the MAPK pathway. However, our results showed no changes in Alix protein expression in CMR-treated cells, which is contrary to the results reported in Han's study [32]. The discrepancy in Alix involvement in CMR-triggered paraptosis suggests the potential involvement of other molecular signaling pathways in paraptosis in lung cancer cells.

Regarding the activation of MAPK signaling, previous studies have shown that exposure of cells to IR and to a variety of other toxic stresses induces simultaneous compensatory activation of multiple MAPK pathways [33]. Interestingly, we observed that radiation treatment combined with CMR enhanced the MAPK pathway and increased the percentage of cytoplasmic vacuolation, which could explain the synergistic effect of CMR combined with irradiation. Most importantly, we found that paraptosis in CMR-treated cancer cells or in cancer cells treated with the combination of CMR and IR was inhibited when the cells were exposed to the specific phospho-Erk inhibitor U0126, indicating the role of MAPK activation in CMR-induced cell killing and paraptosis in NSCLC cells. 


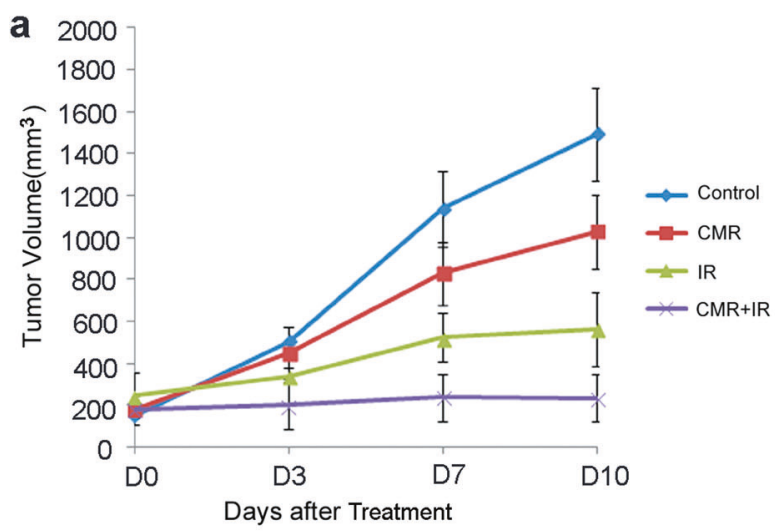

C

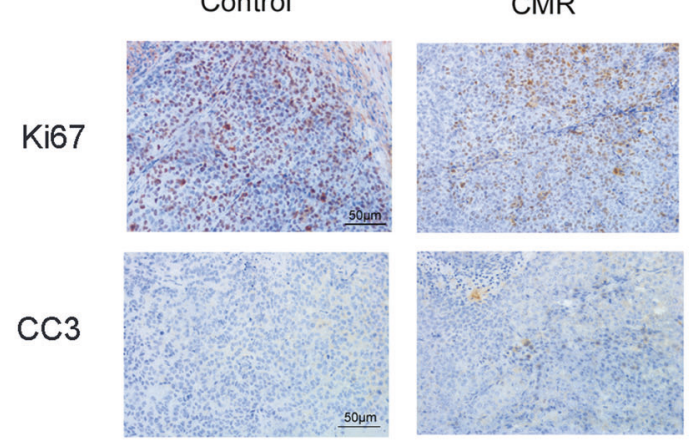

b

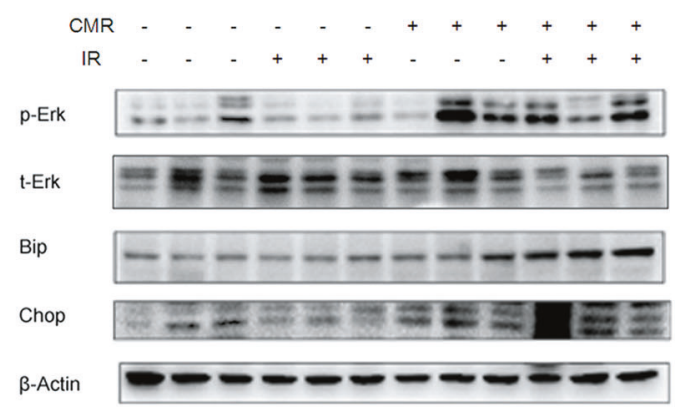

IR

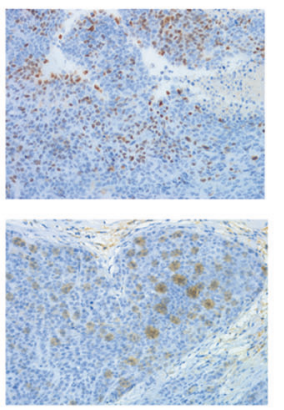

CMR+IR
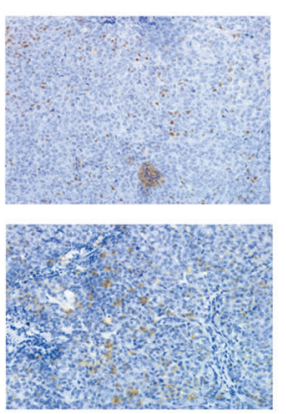

Fig. 6 H460 xenograft tumors were treated with CMR, radiation or the combination. a Tumor growth was measured as described in the Materials and Methods. The growth curves represent the average values of six mice in each group. Error bars indicate the standard deviation. b Western blot. Xenograft tumor tissues were collected after 10 days of the indicated treatments. Western blot analysis was performed to test the changes in p-Erk, Chop and Bip. c Immunohistochemistry analysis of the expression of Ki67 and the apoptotic marker CC3. Positive staining was determined for each group ( $n=3$ animals/group). The scale bar represents $50 \mu \mathrm{m}$, and all images are at the same magnification.

In conclusion, we report for the first time that the anticancer activity and radiosensitization effect of CMR induces paraptosis. Our data suggest that CMR could be considered a potential anticancer agent and radiation sensitizer in future cancer therapeutics.

\section{ACKNOWLEDGEMENTS}

This study was supported by grants from the Zhejiang Provincial Natural Science Foundation (LY19H160032), the National Natural Science Foundation of China $(81602671,81602555)$ and major project of the Hangzhou Science and Technology Bureau (20180417A01).

\section{AUTHOR CONTRIBUTIONS}

SRZ, SLM and XQC designed the research; SRZ, XCZ, JFL and YYZ performed the research study; SRZ, HXH and HMF made the substantial contributions to analysis and interpretation of data; SRZ, HXH and XCZ wrote the paper. All the authors approved the final version and agreed for publication.

\section{ADDITIONAL INFORMATION}

The online version of this article (https://doi.org/10.1038/s41401-019-0351-4) contains supplementary material, which is available to authorized users.

Competing interests: The authors declare no competing interests.

\section{REFERENCES}

1. Rafiemanesh H, Mehtarpour M, Khani F, Hesami SM, Shamlou R, Towhidi F, et al. Epidemiology, incidence and mortality of lung cancer and their relationship with the development index in the world. J Thorac Dis. 2016;8:1094-102.
2. Bianco A, Malapelle U, Rocco D, Perrotta F, Mazzarella G. Targeting immune checkpoints in non small cell lung cancer. Curr Opin Pharmacol. 2018;40:46-50.

3. Lim SM, Syn NL, Cho BC, Soo RA. Acquired resistance to EGFR targeted therapy in non-small cell lung cancer: Mechanisms and therapeutic strategies. Cancer Treat Rev. 2018;65:1-10.

4. Lewis J, Gillaspie EA, Osmundson EC, Horn L. Before or after: evolving neoadjuvant approaches to locally advanced non-small cell lung cancer. Front Oncol. 2018;8:5.

5. Kim MJ, Kwon SB, Ham SH, Jeong ES, Choi YK, Choi KD, et al. H9 inhibits tumor growth and induces apoptosis via intrinsic and extrinsic signaling pathway in human non-small cell lung cancer xenografts. J Microbiol Biotechnol. 2015;25:648-57.

6. Mao D, Liu AH, Wang ZP, Zhang XW, Lu H. Cucurbitacin B inhibits cell proliferation and induces cell apoptosis in colorectal cancer by modulating methylation status of BTG3. Neoplasma. 2019;66:593-602.

7. Rajavel T, Banu Priya G, Suryanarayanan V, Singh SK, Pandima Devi K. Daucosterol disturbs redox homeostasis and elicits oxidative-stress mediated apoptosis in A549cells via targeting thioredoxin reductase by a p53 dependent mechanism. Eur J Pharmacol. 2019;855:112-23.

8. Cheong HT, Xu F, Choy CT, Hui CW, Mok TSK, Wong CH. Upregulation of $\mathrm{Bcl} 2$ in NSCLC with acquired resistance to EGFR-TKI. Oncol Lett. 2018;15:901-7.

9. Zhang $Y$, Lian J, Wang $X$. Actein inhibits cell proliferation and migration and promotes cell apoptosis in human non-small cell lung cancer cells. Oncol Lett. 2018;15:3155-60.

10. Subramani S, Malhotra V. Non-autophagic roles of autophagy-related proteins. EMBO Rep. 2013;14:143-51.

11. Wu H, Che X, Zheng Q, Wu A, Pan K, Shao A, et al. Caspases: a molecular switch node in the crosstalk between autophagy and apoptosis. Int J Biol Sci. 2014;10:1072-83.

12. Kim YJ, Sohn MJ, Kim WG. Chalcomoracin and moracin C, new inhibitors of Staphylococcus aureus enoyl-acyl carrier protein reductase from Morus alba. Biol Pharm Bull. 2012;35:791-5.

13. Nomura T, Fukai T, Hano $Y$, Nemoto K, Terada S, Kuramochi T. Constituents of cultivated mulberry tree. Planta Med. 1983;47:151-6. 
14. Gunawan C, Rizzacasa MA. Mulberry Diels-Alder adducts: synthesis of chalcomoracin and mulberrofuran $C$ methyl ethers. Org Lett. 2010;12:1388-91.

15. Sperandio S, Poksay K, de Belle I, Lafuente MJ, Liu B, Nasir J, et al. Paraptosis: mediation by MAP kinases and inhibition by AIP-1/Alix. Cell Death Differ. 2004;11:1066-75.

16. Mi X, Wang C, Sun C, Chen X, Huo X, Zhang $Y$, et al. Xanthohumol induces paraptosis of leukemia cells through p38 mitogen activated protein kinase signaling pathway. Oncotarget. 2017;8:31297-304.

17. Broker LE, Kruyt FA, Giaccone G. Cell death independent of caspases: a review. Clin Cancer Res. 2005;11:3155-62.

18. Kar R, Singha PK, Venkatachalam MA, Saikumar P. A novel role for MAP1 LC3 in nonautophagic cytoplasmic vacuolation death of cancer cells. Oncogene. 2009;28:2556-68.

19. Gu XD, Sun MY, Zhang L, Fu HW, Cui L, Chen RZ, et al. UV-B induced changes in the secondary metabolites of Morus alba L. leaves. Molecules. 2010;15:2980-93.

20. Fertil B, Dertinger $H$, Courdi A, Malaise EP. Mean inactivation dose: a useful concept for intercomparison of human cell survival curves. Radiat Res. 1984;99:73-84.

21. Ram BM, Ramakrishna G. Endoplasmic reticulum vacuolation and unfolded protein response leading to paraptosis like cell death in cyclosporine $A$ treated cancer cervix cells is mediated by cyclophilin B inhibition. Biochim Biophys Acta. 2014;1843:2497-512.

22. Taniguchi $\mathrm{Y}$, Horiuchi $\mathrm{H}$, Morikawa $\mathrm{T}$, Usui K. Small-cell carcinoma transformation of pulmonary adenocarcinoma after osimertinib treatment: a case report. Case Rep. Oncol. 2018;11:323-9.

23. Zhang L, Peng Y, Uray IP, Shen J, Wang L, Peng $X$, et al. Natural product betathujaplicin inhibits homologous recombination repair and sensitizes cancer cells to radiation therapy. DNA Repair (Amst). 2017;60:89-101.
24. Tomoda K, Tam YT, Cho H, Buehler D, Kozak KR, Kwon GS. Triolimus: a multi-drug loaded polymeric micelle containing paclitaxel, 17-AAG, and rapamycin as a novel radiosensitizer. Macromol Biosci. 2017;17. https://doi.org/10.1002/ mabi.201600194.

25. Ren J, Chu Y, Ma H, Zhang Y, Zhang X, Zhao D, et al. Epigenetic interventions increase the radiation sensitivity of cancer cells. Curr Pharm Des. 2014;20:1857-65.

26. Gewirtz DA, Hilliker ML, Wilson EN. Promotion of autophagy as a mechanism for radiation sensitization of breast tumor cells. Radiother Oncol. 2009;92:323-8.

27. Wang $X, G u$ Y, Liu $H$, Shi L, Sun X. Icotinib hydrochloride enhances chemo- and radiosensitivity by inhibiting EGFR signaling and attenuating RAD51 expression and function in Hela S3 cells. Onco Targets Ther. 2018;11:1245-58.

28. Zhu JJ, Shan JJ, Sun LB, Qiu WS. Study of the radiotherapy sensitization effects and mechanism of capecitabine (Xeloda) against non-small-cell lung cancer cell line A549. Genet Mol Res. 2015;14:16386-91.

29. Cao HY, Ding RL, Li M, Yang MN, Yang LL, Wu JB, et al. Danshensu, a major watersoluble component of Salvia miltiorrhiza, enhances the radioresponse for Lewis Lung Carcinoma xenografts in mice. Oncol Lett. 2017;13:605-12.

30. Limonta P, Moretti RM, Marzagalli M, Fontana F, Raimondi M, Montagnani Marelli $M$. Role of endoplasmic reticulum stress in the anticancer activity of natural compounds. Int J Mol Sci. 2019;20:E961.

31. Sun $Q$, Chen $T$, Wang X, Wei X. Taxol induces paraptosis independent of both protein synthesis and MAPK pathway. J Cell Physiol. 2010;222:421-32.

32. Han H, Chou CC, Li R, Liu J, Zhang L, Zhu W, et al. Chalcomoracin is a potent anticancer agent acting through triggering Oxidative stress via a mitophagy- and paraptosis-dependent mechanism. Sci Rep. 2018;8:9566. https://doi.org/10.1038/ s41598-018-27724-3.

33. Dent $P$, Yacoub A, Fisher PB, Hagan MP, Grant S. MAPK pathways in radiation responses. Oncogene. 2003;22:5885-96. 